Gut, 1987, 28, S1, 169-173

\title{
Pancreatic size and enzyme contents after vagal deafferentation in jejunectomised pigs under free or restricted feeding
}

\author{
J P LAPLACE, AND C SIMOES NUNES
}

From the Laboratoire de Physiologie de la Nutrition, Institut National de la Recherche Agronomique, Jouy-en-Josas, France

SUMMARY A factorial experiment was designed to test under different feeding levels the effects of the surgical deprivation of sensory afferences (deafferentation) arising from the gastrointestinal tract, including the intestinal chemosensitivity, on the jejunectomised pig used as a model. Within 28 days, the limited jejunectomy failed to affect the pancreas and the enzyme activities were not affected by the feeding level (within the limit of $70 \%$ of ad libitum). It was shown that the deafferentation induced significant reductions in the pancreatic tissue mass and in the various enzyme activities, thus suggesting the possible importance of intestinal sensibility for the pancreas.

Recent reviews of the mechanisms responsible for intestinal and pancreatic adaptation after small intestine resection, ${ }^{1-2}$ have stressed the basic role of endoluminal nutrition. This was first suggested many years $\mathrm{ago}^{3}$ and since then, the suggestion has been reinforced by the effects of several manipulations such as ileal transposition, hyperphagia, fasting, small bowel bypass, and enteral $v$ parenteral nutrition. Indeed, the presence of nutrients within the intestinal lumen may well be necessary to support epithelial cell nutrition and growth directly, in course of absorption. ${ }^{4}$ Luminal nutrition could also act together with bile and pancreatic secretions which were first proposed to have trophic effects, in $1970 .^{5}$

The evidence that humoral factors are responsible for compensatory hyperplasia comes from cross circulation studies in the rat ${ }^{6-7}$ and pig. ${ }^{8}$ It includes a humoral mediation of endoluminal factors, in addition to direct local effects. ${ }^{9-11}$ Enteroglucagon now seems to play a major role in intestinal adaptation. ${ }^{12}$ Although cholecystokinin (CCK), when associated with secretin, ${ }^{13}$ can prevent the intestinal mucosal hypoplasia of TPN, its main trophic action is on the pancreas. $^{14}$

The nervous system might also be suspected to play some direct (enteric or central reflexes), or indirect (modulation of regulatory peptides release), role.

Address for correspondence: Dr J P Laplace, Laboratoire de Physiologie de la Nutrition, Institut National de la Recherche Agronomique, F78350 Jouy-enJosas, France.
Indeed, there are differing degrees of compensatory hypertrophy, depending on the composition of the $\operatorname{diet}^{15}$ which could be related to the highly discriminating ability of visceral sensitivity arising from the numerous vagal receptors, including a large variety of chemoreceptors. ${ }^{16}$ The importance of visceral sensitivity has been first evidenced in relation with intestinal adaptation. ${ }^{8}$ The modulation of its role according to the food intake level was also shown in that case. ${ }^{17}$

The aim of the present study was to investigate, using the pig as a model, the significance of vagally mediated intestinal chemosensitivity to endoluminal nutrients as regards pancreatic morphology and exocrine function, after small intestine resection and under various feeding conditions.

\section{Methods}

\section{ANIMALS}

The whole experiment, which lasted 28 days, involved 72 Large White pigs whose initial live weight was $28.6 \pm 0.2 \mathrm{~kg}$ (mean \pm SEM). Pigs were randomly allotted to the 12 combinations resulting from a factorial design including four treatments $\times$ three feeding levels $\times$ six repetitions.

The four treatments were: (1) unoperated controls (C group); (2) jejunectomy (J group); (3) jejunectomy and subtotal vagal deafferentation (J-SD group); (4) jejunectomy and total vagal deafferentation (J-TD 
group). As in previous experiments, ${ }^{8-17}$ the jejunectomy consisted of a limited, $4 \mathrm{~m}$ resection, ending $120 \mathrm{~cm}$ above the ileocaecal junction, with $68 \%$ of the total small intestine length left in situ and end-to-end restoration of intestinal continuity. The vagal deafferentation selectively suppressed afferent impulses originating below the diaphragm but preserved efferent impulses from the brain stem. It was achieved by removing the left nodose ganglion, performing contralateral truncal vagotomy at the level of the diaphragm (subtotal deafferentation) and, in the case of total deafferentation, ${ }^{18}$ by additional transection of the intra-thoracic branches connecting the two vagus nerves.

The three feeding levels were respectively: (i) ad libitum feeding, (ii) $85 \%$ and (iii) $70 \%$ of the ad libitum level. Except for the first seven days after surgery, this was achieved within each repetition, by daily measurement of the true dry matter intake of the four ad libitum fed pigs, and then by calculation for a matched treatment of the quantities to be allotted to the pigs submitted to a restricted feeding. Both controls at the start of the experimental period and operated pigs underwent fasting for two days; then the hierarchy of the three feeding levels was applied according to a postsurgical feeding scale over seven days.

The feed included ground whole wheat $(81.5 \%)$, soya bean meal $(12.0 \%)$, purified wood cellulose $(3.0 \%)$, minerals and vitamins $(3.5 \%)$. It supplied $3618 \mathrm{kcal}$ per $\mathrm{kg}$ dry matter, at a $14.3 \%$ crude protein level.

At the end of the full 28 days period, the pigs were slaughtered under electrical narcosis. The whole pancreas was immediately removed, and deep frozen after recording its wet weight. Pancreatic tissue was then homogenised. Its dry matter content and the tissue enzyme activities of amylase, chymotrypsin, trypsin, apparent and potential lipase were determined. ${ }^{19}$

\section{Results}

FOOD INTAKE AND SOMATIC GROWTH There were significant differences between the feeding groups as the mean daily dry matter intake recorded over the whole period confirmed the expected feeding schedule (maximum deviation: $2 \%$ ). That resulted in the same hierarchy of the mean daily live weight gains, with significant differences between feeding groups. Jejunectomy never significantly reduced the dry matter intake, however, nor the daily mean live weight gain as compared with the homologous Cpigs. Though significantly lower than in the C-pigs, the dry matter intake in J-SD and J-TD pigs was similar to that recorded in the J-pigs. Within a similar
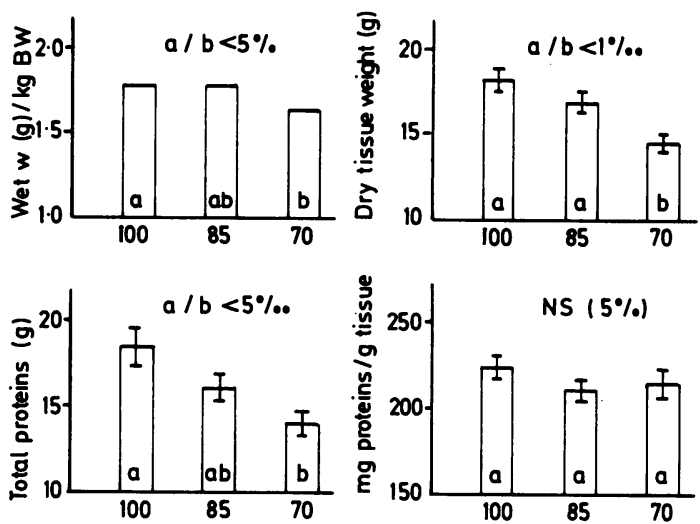

Fig. 1 Effects of the feeding level on the pancreas: mean $( \pm S E M)$ effects independent of the surgical treatments. The values 100,85 and 70 refer to the percentage of ad libitum feeding.
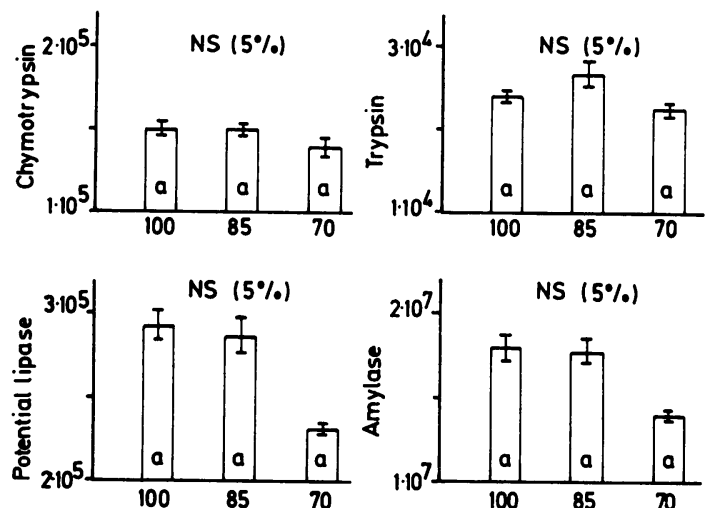

Fig. 2 Effects of the feeding level on total enzyme activities of pancreatic tissue: mean ( $\pm S E M)$ effects independent of the surgical treatments.

feeding group, the live weight gain was similar in $\mathbf{J}$, $\mathrm{J}-\mathrm{SD}$ and J-TD pigs.

\section{PANCREATIC TISSUE}

The effects of the feeding level were limited. While the protein content per gram of pancreatic tissue was unaffected, only the $70 \%$ feeding level significantly reduced the wet and dry weights and the total protein content of the pancreas (Fig. 1). But enzyme activities were not significantly affected by the feeding level (Fig. 2).

As regards the surgical treatments, independent of the feeding level, all values recorded in $\mathrm{J}$ pigs were similar to control values. In contrast, the wet and dry weights of the pancreas and the total pancreatic protein content were significantly reduced 

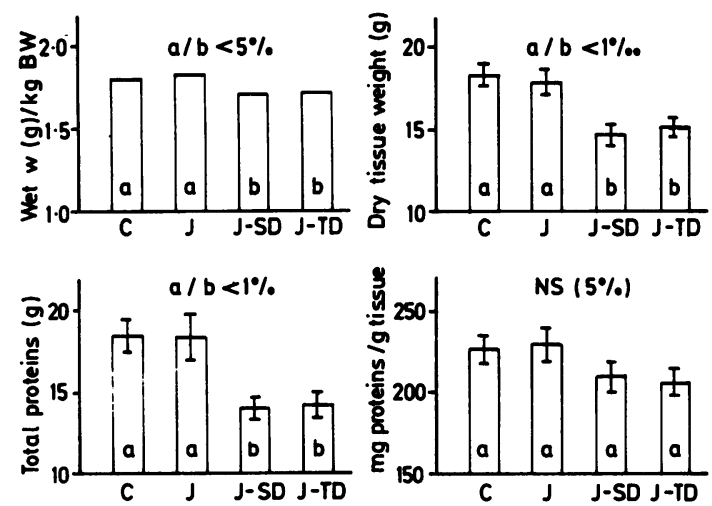

Fig. 3 Effects of the surgical treatments on the pancreas: mean $( \pm S E M)$ effects independent of the feeding level. $C=$ control pigs $; J=$ jejunectomised pigs $; J-S D=$ pigs submitted to jejunectomy and subtotal deafferentation; $J-T D=$ jejunectomy and total deafferentation.
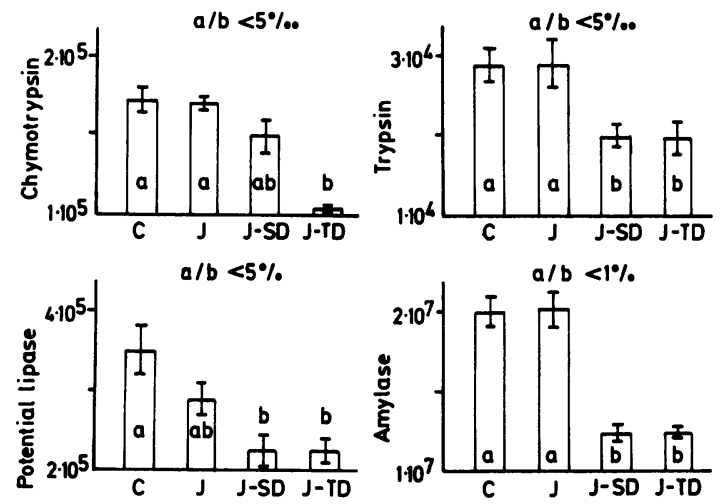

Fig. 4 Effects of the surgical treatments on total enzyme activities of pancreatic tissue: mean ( $\pm S E M)$ effects independent of the feeding level. For explanations see Figure 3.

in J-SD and J-TD pigs while the protein content per gram of pancreatic tissue was not modified (Fig. 3). In addition, the total enzyme activities of trypsin, chymotrypsin, amylase and lipase were significantly depressed in J-SD and J-TD pigs (Fig. 4), as well as the corresponding specific, and per gram of tissue, enzyme activities. There was no significant interaction between the feeding level and the surgical procedures tested.

\section{Discussion}

Relatively little is known regarding the exocrine pancreas after small intestine resection, except for massive resections in the rat. ${ }^{20-21}$ According to our results, a limited distal jejunectomy does not affect the pancreas of the pig when performed alone.

As regards intestinal adaptation, despite a reduced intake after surgery, there may be a relative nutrient overload of residual segments after massive resection, able to induce compensatory hypertrophy in connection with other trigger mechanisms. Meanwhile, as the pancreas supplies the main enzymes responsible for hydrolysis of food components, pancreatic exocrine function has to be adjusted to the total intake. ${ }^{22}$ This ability seems to be preserved, even under the most severe food restriction $(70 \%$ of $a d$ libitum) as all enzyme activities were not significantly modified despite a reduced weight and total protein content of the pancreas. These results after a long term restriction are quite different from the effects of a short term starvation for example, as reviewed by Solomon. ${ }^{22}$ Our data however would suggest that the nervous and humoral factors triggering pancreatic exocrine function are still active even under restricted feeding.

Our experiment allowed us to test accurately the effects of vagal deafferentation on the pancreas in jejunectomised pigs as both the jejunectomy and the food intake level failed to induce any significant disorder of pancreatic function.

In contrast, the vagal deafferentation, either subtotal or total, induced both a morphological (reduced weight and total proteins) and functional (enzyme activities) lessening of the pancreatic tissue. The question arises as to whether these effects result directly from the nervous dysfunction or indirectly from a secondary humoral dysfunction, or both. Moreover, the effects recorded on the pancreas could be direct effects on this target organ as well as indirect effects resulting from the consequences of vagal deafferentation in jejunectomised pigs - that is, impaired compensatory hypertrophy. ${ }^{17}$

By analogy, let us recall that some intestinal hypoplasia has been reported after total abdominal vagotomy in dogs ${ }^{23-24}$ but postresectional compensatory mechanisms were still found to operate after bilateral truncal vagotomy. ${ }^{25}$ Bilateral subdiaphragmatic vagotomy was shown to inhibit and delay DNA synthesis and proliferation of liver cells after partial hepatectomy. ${ }^{26}$ As regards the pancreas itself, while reduced tissue weights and tissue enzyme activities were found in pigs 28 days after vagal deafferentation, a trophic effect was recently recorded ${ }^{27}$ in rats three months after bilateral truncular vagotomy (increased weight by $40 \%$ and increased enzyme concentrations). Nevertheless, vagal deafferentation is very different from truncular vagotomy because one only suppresses the afferent stimuli to the central nervous system and preserves efferent impulses to the digestive tract. In addition, it should be noted that the 
delayed gastric emptying induced by vagal deafferentation, ${ }^{28}$ which limits food delivery to the duodenum, could be considered in some way as a food restriction. In the rat, ${ }^{27}$ however, gastric stasis was also observed in most of vagotomised animals, and the trophic effect of vagotomy was the most pronounced in rats with severe stomach distension.

Another interesting hypothesis is related to the possible pancreaticotrophic function of CCK which can be suspected from the literature. ${ }^{2}$ Increased concentrations of CCK and a change in the temporal pattern of the release of CCK as well as an increase in basal concentrations of pancreatic polypeptide were reported after intestinal resection in dogs. ${ }^{29}$

Thus the question of the effects of vagal deafferentation on the circulating levels of certain regulatory peptides after small intestine resection arises. Although jejunectomy in itself does not affect the pancreas, it might be that a postresectional impaired CCK response was responsible for the recorded pancreatic dysfunction. Conversely it might be that the pancreatic dysfunction after vagal deafferentation was in some way the cause of the impairment of compensatory hypertrophy. Further experiments are needed therefore to elucidate the underlying mechanisms.

\section{References}

1 Williamson RCN. Intestinal adaptation. (2) Mechanisms of control. $N$ Engl J Med 1978; 298: 1444-50.

2 Laplace JP. Déterminisme neurohumoral de l'adaptation de l'intestin résiduel après entérectomie. Reprod Nutr Dév 1983; 23: 641-77.

3 Dowling RH, Booth CC. Structural and functional changes following small intestinal resection in the rat. Clin Sci 1967; 32: 139-49.

4 Dowling RH, Gleeson MH. Cell turnover following small bowel resection and bypass. Digestion 1973; 8: 176-90.

5 Altmann GG, Leblond CP. Factors influencing villus size in the small intestine of adult rats as revealed by transposition of intestinal segments. Am J Anat 1970; 127: $15-36$.

6 Loran MR, Carbone JV. The humoral effect of intestinal resection on cellular proliferation and maturation in parabiotic rats. In: Sullivan MF, ed. Gastrointestinal radiation injury. Amsterdam: Excerpta Medica, 1968: 127-38.

7 Williamson RCN, Buchholtz TW, Malt RA. Humoral stimulation of cell proliferation in small bowel after transection and resection in rats. Gastroenterology 1978; 75: $249-54$

8 Laplace JP. Compensatory hypertrophy of the residual small intestine after partial enterectomy. A neurohumoral feedback? Ann Rech Vet 1980; 11: 165-77.

9 Morin CL, Ling V, Van Caillie M. Role of oral intake on intestinal adaptation after small bowel resection in growing rats. Pediatr Res $1978 ; 12$ : 268-71.
10 Williamson RCN, Bauer FLR. Evidence for an enterotropic hormone: compensatory hyperplasia in defunctioned bowel. Br J Surg 1978; 65: 736-9.

$11 \mathrm{Li}$ AKC, Jeppsson BW, Jamieson CG. Intraluminal versus humoral factors in intestinal cell proliferation. $\mathrm{Br}$ J Surg 1982; 69: 569-72.

12 Bloom SR, Polak JM. The hormonal pattern of intestinal adaptation. A major role for enteroglucagon. In: Polak JM, Bloom SR, Wright NA, Daly MJ, eds. Adaptation pathophysiology of intestinal response to disease. Scand J Gastroenterol 1982; 17 suppl. 74: 93-103.

13 Hughes CA, Bates T, Dowling RH. Cholecystokinin and secretin prevent the intestinal mucosal hypoplasia of total parenteral nutrition in the dog. Gastroenterology 1978; 75: 34-41.

14 Hughes CA, Breuer RS, Ducker DA, Hatoff DE, Dowling RH. The effect of cholecystokinin and secretin on intestinal and pancreatic structure and function. In: Robinson JWL, Dowling RH, Riecken EO eds. Mechanisms of intestinal adaptation. Lancaster: MTP Press, 1982: 435-450.

15 Morin CL, Grey VL, Garofalo C. Influence of lipids on intestinal adaptation after resection. In: Robinson JWL, Dowling RH, Riecken EO. Mechanisms of intestinal adaptation. Lancaster: MTP Press, 1982: 175-84.

16 Mei N. Intestinal chemosensitivity. Physiol Rev 1985; 65: 211-37.

17 Laplace JP. Impairment by vagal deafferentation of the compensatory hypertrophy after enterectomy, at high and low feeding levels. In: Robinson JWL, Dowling RH, Riecken EO, eds. Mechanisms of intestinal adaptation. Lancaster: MTP Press, 1982: 321-31.

18 Laplace JP. Surgical deprivation of vagal afferences from the gastrointestinal tract of the pig; clinical and EMG studies. In: Christensen J, ed. Gastrointestinal motility, New York: Raven Press, 1980: 145-152.

19 Simoes Nunes C, Corring T. Pancreatic exocrine secretion in the pig following test meals of different composition and intraduodenal loads of glucose and maltose. Horm Metab Res 1979; 11 : 346-51.

20 Gelinas MD. Exocrine pancreatic function and structure following proximal intestinal resection. McGill University: Ph D Thesis, 1978.

21 Stock C, Marescaux J, Haegel P, Aprahamian M, Lhoste E, Grenier JF. Comparative effect of small bowel bypass and resection on the rat exocrine pancreas and the intestinal enzyme activities. In: Robinson JWL, Dowling RH, Riecken EO, eds. Mechanisms of intestinal adaptation. Lancaster: MTP Press, 1982: 453-61.

22 Solomon TE. Pancreatic adaptation: physiological and pathophysiological aspects. In: Robinson JWL, Dowling RH, Riecken EO, eds. Mechanisms of intestinal adaptation. Lancaster: MTP Press, 1982: 495-503.

23 Ballinger WF, Iida J, Aponte GE, Wirts CW, Goldstein F. Structure and function of the canine small intestine following total abdominal vagotomy. Surg Gynecol Obstet 1964; 118: 1305.

24 Silen W, Peloso O, Jaffe BF. Kinetics of intestinal epithelial proliferation: effect of vagotomy. Surgery 1966; 60: 127-35.

25 Oscarson JEA, Veen HF, Williamson RCN, Ross JS, Malt RA. Compensatory postresectional hyperplasia 
and starvation atrophy in small bowel : dissociation from endogenous gastrin levels. Gastroenterology 1977; 72: 890-5.

26 Kato H, Shimazu T. Effect of autonomic denervation on DNA synthesis during liver regeneration after partial hepatectomy. Eur J Biochem 1983; 134: 473-8.

27 Koop H, Schwarting H, Trautmann M, et al. Trophic effect of truncal vagotomy on the rat pancreas. Digestion
1986; 33: 198-205.

28 Laplace JP, Cuber JC. Déafférentation vagale totalє et évacuation gastrique chez le porc. Reprod Nutr Dev $1984 ; 24: 655-70$.

29 Lilja P, Wiener I, Inoue K, Thompson JC. Changes in circulating levels of cholecystokinin, gastrin, and pancreatic polypeptide after small bowel resection in dogs. Am J Surg 1983; 145: 157-63. 